\title{
Imperfect Competition in the Recycling Industry
}

\section{Thomas EICHNER*}

\author{
FB 5, VWL IV, University of Siegen \\ Hoelderlinstr. 3, D-57068 Siegen, Germany \\ Phone: +49-271-740 3164 \\ Fax: $+49-271-7402732$ \\ e-mail: eichner@vwl.wiwi.uni-siegen.de
}

forthcoming, Metroeconomica

\begin{abstract}
This paper studies the market allocation in an economy where material is used for producing a consumption good, then recycled and finally landfilled, and where a recycling firm has market power. The material content constitutes an aspect of green product design and affects the recycling costs. Although the recycling firm's supply of recycling services is inefficiently low, she does not abuse her market power to distort the product design allocation. Different policy schemes are proposed which correct for market failures. One promising candidate is a relative recycling standard combined with a consumption good's tax, a material subsidy and a subsidy on recycling services.

JEL classification: H21, L12, Q28

key words: $\quad$ imperfect competition, recycling, product design
\end{abstract}

*Financial support by Deutsche Forschungsgemeinschaft (DFG) is gratefully acknowledged. I appreciate the helpful comments by Rüdiger Pethig, Marco Runkel and an anonymous referee. The usual disclaimer applies. 


\section{Introduction}

In recent years many countries made strong efforts to stimulate recycling in order to reduce the waste flow. A prominent case in point is Germany where waste management was reorganized according to the German green dot programme from 1990 and the Law of Circular Material Flows (Kreislaufwirtschafts- und Abfallgesetz) from 1996. ${ }^{1}$ Close related to the problem of waste avoidance is the question of how designing products greener such that they are better recyclable. Existing studies have contributed to the understanding of product design and recycling. The analyses have been carried out in static partial or general equilibrium models encompassing the whole life-cycle of a consumption good and assuming that agents act under perfect competition. Different facets of product design have been investigated: Fullerton and Wu (1998) and Choe and Fraser (1999) focus on disassembly properties of consumption goods, Eichner and Pethig's (2001a, b) product design is the material mix whereas Calcott and Walls (2000) analyze the impact of weight on recycling activities. Each paper suggests various tax-subsidy policies to achieve efficient levels of product attributes, recycling and waste treatment. To be more specific, in absence of functioning markets for product attributes, an output tax and a subsidy of recycled material, both instruments together are also refered to as deposit-refund system, restore efficiency. In case of material mix the regulator needs in addition to the deposit-refund system a material subsidy.

In this paper we extend prior contributions in two directions:

(a) we introduce imperfect competition and

(b) we check the efficiency performance of relative recycling standards.

Closer inspection of the past of the German green dot reveals that the government made producers responsible for taking back consumption residuals for further orderly waste processing. Take-back is applied to packagings, but not to all consumption residuals. As a consequence Germans have two rubbish bins: one for packagings, e.g. yoghurt beakers or milk bottles, and one for the rest, e.g. for light bubes, dirt, ashes and so on. In order to carry out the mandatory take-back obligation (packaging) producers established the waste management organization Duales System Deutschland (DSD) which is a middleman between producers and recyclers. It is indeed dualistical since the disposal of packaging waste takes place parallel to the disposal of other waste. In Germany the disposal of non-packaging waste is incumbent on local municipals while the DSD is responsible for the collection, separation and recycling of packaging waste. In practise the DSD instructs local municipalities which play the role of a second middlemen to take over the organization of

\footnotetext{
${ }^{1}$ For more details see e.g. Roussa and Sha (1994) and Holm-Mueller (1996).
} 
packaging waste disposal. Then local municipalities make a contract with individual waste haulers to collect waste, sort it, and transport it to a recycling firm. The high collection cost's (which are fix costs) share of total costs and the spatial dimension of collection and recycling give evidence that (regional) recycling firms have market power. It is observable that in a given spatial territory which encompasses many municipals the associated municipalities obligate a single or few recycling firms and, in addition, instructions are laid down in long-term contracts. Therefore, in our view, the study of regional recycling monopolies or oligopolies is of special interest. As a first step towards imperfect competition we restrict our attention to the monopoly case. ${ }^{2}$ In addition, we refrain from the before mentioned institutional facts and for the sake of simplicity assume that producers and recyclers do buisiness with each other without using middlemen.

\begin{tabular}{l|c|c|c|c}
\hline & \multicolumn{4}{|c}{ relative recycling standards } \\
material & 1993 & 1995 & 1996 & 1998 \\
\hline glas & 42 & 72 & 70 & 75 \\
ppk & 18 & 64 & 60 & 70 \\
aluminium & 18 & 72 & 50 & 60 \\
metal & 26 & 72 & 70 & 70 \\
compounds & 6 & 64 & 50 & 60 \\
plastics & 9 & 64 & 50 & 60 \\
\hline
\end{tabular}

Table 1: Recycling standards

In environmental economics theorists favor indirect regulation through appropriate price signals (taxes, subsidies, charges, fees, administrative prices etc.). In contrast politicians and bureaucrats prefer direct regulation through command- and control regulatory standards. In particularly, relative standards possess advantages in comparison to environmental taxes. Their implementation and monitoring is much simpler and therefore the administrative costs of relative standards are lower than those of environmental taxes. The above mentioned product design literature reflects this situation. Since the articles are written from theorists they deal with taxes and subsidies, none of them deals with standards. ${ }^{3}$ In practise of the DSD we find a relative recycling standard which is a restriction on the quantity of recycled material per unit of material embodied in consumption

\footnotetext{
${ }^{2}$ In the U.S. the market power of an virgin material producer who controls the aluminum market and forces the aluminum price on competitive firms in secondary markets is also of special interest, see Grant (1999) and Gaudet and Van Long (1999). The interest is motivated by the familiar Alcoa antitrust case. Although this case is very interesting, our focus lies more on the recycling of packaging waste in Europe and thus the Alcoa antitrust case is beyond the scope of our paper.

${ }^{3}$ An exception builds Mommer (2000) who examined the allocative impact of a waste standard. Waste disposal is organized by identical oligopolistic disposers but Mommer (2000) abstains from analyzing recycling and product design issues.
} 
residuals levied on the monopolistic recycler. Table 1 (Staudt et al. (1997, p. 27)) lists relative recycling standards relative to packaging materials. All materials have in common that their relative recycling standards rose over the last 5 years.

In the present paper we elaborate a partial equilibrium model in which a consumption good is produced, consumed, recycled and finally landfilled. Next to the amount of the consumption good the producer determines the product design, i.e. the material content which increases the productivity of the recycling process. Producers and households act under perfect competition whereas the recycling firm is assumed to have monopoly power on the recycling service market. In the economy there are three possible sources of market failures: (a) environmental externality; (b) imperfect competition; and (c) product design externality. The product design literature tells us that in presence of (c) producers choose product design inefficiently low. Buchanan (1969) and Barnett (1980) studied (a) and (b) in a very simple model consisting of a monopolistic producer who generates an environmental externality. Carrying over their results to our model we would expect that (a) induces the recycler to oversupply recycling services whereas (b) makes sure that the recycler undersupplies recycling services. However, from Sheshinsky (1976) it is known that when endogenizing a product characteristica results under (b) are no longer unambiguous. Then it is natural to ask what happens with the recycling services in our setting: Is there a underor overprovision of recycling services? Uses the recycler improperly her market power to affect product design? Next to allocation issues, our second main concern is to check the performance of different efficiency restoring policies, in particular the performance of a relative recycling standard.

The article is organized as follows. In the next section we present the model and characterize the social optimum. Section 3 derives the market allocation and section 4 proceeds with comparing the allocation when markets fail due to (a) - (c) with the efficient allocation. In addition, in section 4 we elaborate tax-subsidy policies which correct for the market failures. Since policy schemes suggested in section 4 are merely implementable for practical and political reasons, section 5 turns to standards combined with tax-subsidy schemes.

\section{The Model and the Social Optimum}

Our model is partial equilibrium in nature. In the production sector the amount $y$ of a consumption good is produced using material and labor. Next to the output level $y$ producers determine a product attribute $q$. We can interpret $q$ generally as product design or green design, but since our focus is on recycling $q$ stands for recyclability and material 
content $^{4}$, respectively. The producers' cost function is given by

$$
C(y, q)=y F(q)
$$

where $F(q)$ are the unit production costs if the consumption good has the material content $q$. The unit production cost function is assumed to be u-shaped. In the appendix I we provide a microfoundation of the cost function (1) and its properties which is based on linear homogeneous production functions.

After consumption, the consumption good is turned into consumption residuals of same weight. Residuals are collected at households and then separated and recycled. ${ }^{5}$ The recycling sector uses labor, residuals $y$ and the material content of residuals $q$ as inputs to generate recycled material $r$ and recycling waste $w$ which add up in terms of weight

$$
r+w=y \text {. }
$$

As mentioned before the residuals' material content improves the recycling productivity, to be more precise increasing $q$, enhances the quantity of recycled material $r$. Introducing the recycling ratio $\alpha$ defined as the share of recycled material $r$ per unit of the material embodied in residuals $q y$ allows us to express recycled material as

$$
r=\alpha q y
$$

and recycling waste as

$$
w=y(1-\alpha q)
$$

Now we turn to the recycling firm's revenue and cost structure. We denote by $N$ the netrecycling cost function of the recycler which consists of revenues from the sale of recycled material less labor costs. ${ }^{6}$ The net-recycling cost function is assumed to take the form

$$
N(y, q, \alpha)=y G(q, \alpha)
$$

where $G(q, \alpha)$ are the net-unit recycling costs if residuals have material content $q$ and if the recycling ratio is $\alpha$. We do not restrict the partial derivatives of the functions $N$ and $G$ with respect to $q$ and $\alpha$ but instead the inequality

$$
\alpha G_{\alpha}-q G_{q}>0
$$

\footnotetext{
${ }^{4}$ In terms of the model presented in appendix I $q$ is the embodied material per unit of output.

${ }^{5}$ To avoid clumsy phrases in the remainder of the paper our notion of recycling encompasses collecting and separating activities.

${ }^{6}$ Obviously, the recycling firm obtains revenues from residuals and faces costs caused by residuals' material content, too. These revenues/costs are taken into account in the market economy developed in section 3 , but via assumption they do not enter the net-recycling cost function $N$.
} 
will prove to be helpful in the subsequent analysis. The interested reader is refered to appendix I where (5) is microfounded and (6) is shown to be satisfied if recycling functions are linear homogeneous. At the end of the consumption good's life-cycle recycling waste is landfilled at linear cost $c^{w} w$.

Consumers' preferences are reflected in the linear market inverse demand function $P(y)=\beta-\delta y$ depending on the consumption good and in the social damage function which reflects environmental degradation caused by landfilled waste. For the sake of simplicity the damage function is assumed to be linear in total landfilled waste and thus is specified as $c^{d} w$.

Having completed the description of the model we now focus on the socially optimal allocation which follows from maximizing the welfare

$$
W(y, q, \alpha)=\int_{0}^{y}(\beta-\delta s) d s-y F(q)-y G(q, \alpha)-\left(c^{w}+c^{d}\right)(1-\alpha q) y .
$$

The first-order conditions for interior solutions can be written for the optimal allocation $\left(y^{*}, q^{*}, \alpha^{*}\right)$ as

$$
\begin{gathered}
\beta-\delta y^{*}=F\left(q^{*}\right)+G\left(q^{*}, \alpha^{*}\right)+\left(c^{w}+c^{d}\right)\left(1-\alpha^{*} q^{*}\right), \\
F_{q}+G_{q}=\left(c^{w}+c^{d}\right) \alpha^{*}, \\
G_{\alpha}=\left(c^{w}+c^{d}\right) q^{*} .
\end{gathered}
$$

All three first-order conditions are of type marginal benefits equal to marginal costs. Eq. (8) determines the efficient allocation of the consumption good which is attained if the consumers' marginal willingness-to-pay for the consumption good (LHS) equals the sum of its unit production costs $\left(F\left(q^{*}\right)\right)$, net-unit recycling costs $\left(G\left(q^{*}, \alpha^{*}\right)\right)$, marginal environmental damage $\left(c^{d}\left(1-\alpha^{*} q^{*}\right)\right)$ and marginal landfilling costs $\left(c^{w}\left(1-\alpha^{*} q^{*}\right)\right)$. Similarly Eq. (9) governs the efficient allocation of material content. The RHS of Eq. (9) reflects the marginal benefits of increasing material content. In view of (4) increasing $q$ ceteribus paribus leads to a reduction of waste which in turn saves landfilling costs and diminishes the environmental damage. The LHS of Eq. (9) represents the associated marginal unit production costs and net-unit recycling costs. Eq. (10) states that the marginal cost reduction through diminishing the recycling ratio is equal to the sum of marginal landfilling costs and marginal environmental damage, all per unit of output.

\section{Markets}

In this section we turn to the allocation of resources via markets. Consumers only acquire the right to consume when they buy good $Y$ at price $p^{y}$ in the the market place while 
the physical units of good $Y$ and the consumption residuals remain the property of the producers. Hence the producers are responsible for the orderly disposal of those residuals. This institutional arrangement is known as producer responsibility or as take-back mandate. Take-back is put into action in European countries and Japan. The best-known example is the German packaging waste organization. ${ }^{7}$ After consumption the producers which are the owner of the residuals pass them on to the recycling firm which supplies recycling services. The recycler offers the contract $\tilde{P}(q) y$ for providing $y$ units of recycling services at given material content $q . \tilde{P}(q)$ is a (hedonic) price function which need not to be linear and reflects the recyler's willingness to pay for the material content which affects the secondary material generation.

Recycling waste collection and landfilling is organized by a public enterprise that sets the disposal charge $p^{w}$ equal to marginal costs and adjusts the charge until the recycler's supply of recycling waste matches the landfiller's demand, formally

$$
p^{w}=c^{w}
$$

Consumers and producers act under perfect competition whereas the recycling firm is assumed to have market power. We proceed by revealing the (representative) producer's demand for recycling services. For that purpose consider the producer's profit

$$
\Pi^{y}=\left[p^{y}-\tau^{y}-\tilde{P}(q)\right] y-y F(q)+\sigma^{m} q y
$$

where $\tau^{y}$ is a tax levied on the consumption good and $\sigma^{m}$ is a material subsidy. The first-order conditions

$$
\begin{gathered}
p^{y}-\tau^{y}-\tilde{P}(q)-F(q)+\sigma^{m} q=0, \\
-F_{q}+\sigma^{m}-\tilde{P}_{q}=0
\end{gathered}
$$

determine the producer's decisions with respect to the consumption good and the material content. Taking into account that $p^{y}=\beta-\delta y$ we infer from (13)

$$
\tilde{P}(q)=\beta-\delta y-F(q)-\tau^{y}+\sigma^{m} q=: \bar{P}(y, q)
$$

where $\bar{P}(y, q)$ is the producer's inverse demand function for recycling services $y$ which depends on the material content $q$. Since the cost functions (1) and (5) imply that the producer's profit is linear in $y$, the recycler exactly siphons off this profit.

The inverse demand function is known by the monopolistic recycler who offers the recycling services for residuals. Denoting by $p^{w}, \tau^{w}$ and $\sigma^{r}$, a landfilling charge, a waste tax and a subsidy on recycled material, respectively, the recycler's profit is

$$
\Pi^{r}=\bar{P}(y, q) y-y G(q, \alpha)-\left(p^{w}+\tau^{w}\right)(1-\alpha q) y+\sigma^{r} \alpha q y .
$$

\footnotetext{
${ }^{7}$ For more explanation we refer to the introduction.
} 
Maximizing (16) and combining the resulting first-order conditions with (11), the inverse demand function (15) and its partial derivatives, we obtain the first-order conditions which characterize the market allocation under regulation

$$
\begin{gathered}
\beta-2 \delta y=F(q)+G(q, \alpha)+\tau^{y}-\sigma^{m} q+\left(c^{w}+\tau^{w}\right)(1-\alpha q)-\sigma^{r} \alpha q, \\
F_{q}+G_{q}=\left(c^{w}+\tau^{w}+\sigma^{r}\right) \alpha+\sigma^{m}, \\
G_{\alpha}=\left(c^{w}+\tau^{w}+\sigma^{r}\right) q .
\end{gathered}
$$

For $\tau^{y}=\tau^{w}=\sigma^{m}=\sigma^{r}=0(17)$ - (19) simplify to

$$
\begin{gathered}
\beta-2 \delta y=F(q)+G(q, \alpha)+c^{w}(1-\alpha q), \\
F_{q}+G_{q}=c^{w} \alpha, \\
G_{\alpha}=c^{w} q .
\end{gathered}
$$

The allocation rule of the monopolist's supply of recycling services (20) requires marginal revenue $\left(M R(y):=P(y)-P^{\prime}(y) y=\beta-2 \delta\right)$ from a differential increase in $y$ (LHS) to be equal to the corresponding marginal costs (RHS) consisting of unit production costs, net-unit recycling costs and marginal landfilling costs. (21) determines the monopolist's allocation of $q$ which is attained if the sum of marginal unit production costs and marginal net-unit recycling costs of increasing $q$ equals the saved marginal landfilling costs of increasing $q$. In a similar way (22) rules the monopolist's allocation of the recycling ratio $\alpha$.

\section{Market Failures and Efficiency-Restoring Tax-Subsidy Schemes}

Comparing (8) - (10) and (20) - (22) it is worth mentioning that in our economy there are different sources for inefficiency presupposed all policy instruments are set equal to zero:

(a) environmental externality. The environmental damage caused by waste and suffered by the consumers is ignored by the recycler. Formally, in (20) - (22) the marginal environmental damage $c^{d}$ is absent.

(b) imperfect competition. The recycling firm has market power with respect to recycling services. The allocation rule of $y^{*}$, equation (8), requires the price $P\left(y^{*}\right)=\beta-\delta y^{*}$ to be equal to marginal costs, whereas the recycler chooses $y$ such that marginal revenues $M R(y)=\beta-2 \delta y$ are equal to marginal costs, see (20). 
(c) product design externality. The material content of residuals affects recycler's netcosts (5) but is chosen by the producer irrespective of the recycler's needs or wants. This case arises if the indirect market for material content does not exist ${ }^{8}$, formally if $\tilde{P}_{q}=0$.

The plan of investigation in this section is as follows: In subsection 4.1 we report on tax-subsidy schemes which correct for the environmental externality. Since the internalization of the environmental externality has been extensively studied in literature, this is done as concise as possible. In subsection 4.2 we turn to the imperfect competition distortion and compare the monopoly allocation with the socially optimal allocation presupposing all other externalities are internalized and then we discuss efficiency restoring tax-subsidy schemes. Finally, in subsection 4.3 we consider the case at which the market for product design breaks down, characterize the resulting allocation and search for policies internalizing both the product design and the imperfect competition externality.

\subsection{Environmental Externality}

Suppose now in the economy there is only an environmental externality whereas all other externalities are absent. Then the allocation of the perfectly competitive economy is characterized by

$$
\beta-\delta y=F(q)+G(q, \alpha)+\tau^{y}-\sigma^{m} q+\left(c^{w}+\tau^{w}\right)(1-\alpha q)-\sigma^{r} \alpha q,
$$

and (18)-(19). In the presence of an environmental externality the first-best policy requires an environmental tax, see Baumol and Oates (1988), which in our model is a waste tax and has to be set ${ }^{9}$

$$
\tau^{w}=c^{d}, \quad \sigma^{m}=\sigma^{r}=\tau^{y}=0
$$

Because of the relative ease of disposing illegally of waste, a Pigouvian waste tax could have unwelcome repercussions. The tax would necessarily have to be accompanied by a penalty for moonlight dumping. However, enforcement would be difficult and extremely costly. Due to these reservations against the Pigouvian waste tax it is neglected in the subsequent analysis.

Recently, Fullerton and Wolverton (2000) suggested the so-called deposit-refund system consisting of a tax on the consumption good (deposit) and a subsidy on recycling

\footnotetext{
${ }^{8}$ In the first-order conditions (20) - (22) the product design externality is internalized through the price signal $\tilde{P}_{q}$ which is set $\tilde{P}_{q}=-F_{q}<0$, compare (14). Therefore, the first-order conditions for $\tilde{P}_{q}=0$ are elaborated in the analysis of subsection 4.3.

${ }^{9}$ Obviously, if taxes and subsidies are set as in (24) Eqs. (23), (18) and (19) coincide with (8)-(10) which proves that the pertinent allocation is efficient.
} 
(refund) as a favorable alternative to the Pigouvian waste tax. In terms of our model the output tax and the recycled material subsidy at rates

$$
\tau^{y}=\sigma^{r}=c^{d}, \quad \sigma^{m}=\tau^{w}=0
$$

take care of the deposit-refund system.

\subsection{Imperfect Competition}

In this subsection the imperfect competition distortion is our centre of interest. From the textbook treatment of Tirole (1988) it is well known that a monopolist undersupplies the economy with her produced good, since the monopolist's profit maximization implies that the supplied quantity falls short of the socially optimal quantity which is identical to that provided under perfect competition. Unfortunately, this result is not robust if a monopolistic firm sets both quantity and quality of a product. Sheshinsky (1976) has shown that endogenizing quality results are no longer unambiguous. Even the case that both the monopoly quality and the monopoly quantity are higher than the socially levels cannot be excluded. However, in our model we obtain ${ }^{10}$

Proposition 1. Set $\tau^{y}=\sigma^{r}=c^{d}, \sigma^{m}=\tau^{w}=0$. Then

(a) the material content and the recycling ratio emerging in the monopoly will be the same as the socially optimal levels of material content and recycling ratio, ${ }^{11}$

(b) the amount of recycling services chosen by the monopolist is half of the socially optimal recycling services.

Clearly, in proposition 1 the externality (a) is internalized by the deposit-refund system and the product design externality is guided by the hedonic price function in order to fully concentrate on imperfect competition. Proposition 1 can be interpreted in the way that the choice of product design and the recycling ratio are the same under monopoly and under perfect competition. As argued in the introduction the economists' intuition is that the recycling monopolist tends to lessen the material content and generates a lower recycling ratio compared with material content and recycling ratio under perfect competition. Thus, proposition 1 comes as a surprise and reveals that the recycling firm exploits market power not to distore product design. This result is derived under assumptions levied on production

\footnotetext{
${ }^{10}$ The proofs of propositions $1-5$ can be found in appendix II.

${ }^{11} \mathrm{~A}$ referee pointed out that the first part of proposition 1 (a), namely the the independence of $q$ from the market structure, could alternatively be obtained with marshallian assumptions ( $n$ identical producers) and $\mathrm{u}$-shaped average cost curves in $y$.
} 
and recycling technologies which, in our view, are not very restrictive, since homogeneous production functions are quite often employed both in theoretical and in applied analyses.

Since imperfect competition results in an undersupply of recycling services, there is a straightforward possibility to increase demand of and supply for residuals' towards their efficient level.

Proposition 2. Set $\sigma^{r}=c^{d}, \tau^{y}=c^{d}-\delta y^{*}$ and $\sigma^{m}=\tau^{w}=0$. Then the pertinent allocation is efficient.

By imposing a deposit-refund system $\left(\tau^{y}, \sigma^{r}\right)$ the regulator can achieve the socially optimal levels $\left(y^{*}, q^{*}, \alpha^{*}\right)$. The policy instrument $\tau^{y}$ is the sum of marginal environmental damage and the deviation from the consumption good's price of the marginal revenue, i.e. $M R\left(y^{*}\right)-P\left(y^{*}\right)=-\delta y^{*}$. The first term is positive and internalizes the environmental externality. The second term is negative so as to make the recycling firm behave in a competitive way by subsidizing the difference between price and marginal revenue. Apriori it is not clear whether $\tau^{y}$ is a subsidy or a tax. Correcting for imperfect competition calls for subsidizing good $Y$ whereas internalizing the environmental externality requires to tax the consumption good. If the imperfect competition distortion overcompensates the environmental distortion (in extreme case assume that $\left.c^{d}=0\right) \tau^{y}$ turns out to be a subsidy. An output subsidy is a very unpopular policy instrument because making output subsidies clear to voters is, in our view, extremely difficult. This led us to conclude that politicians who intend to be reelected will refrain from output subsidies if there is any alternative. ${ }^{12}$ Since both $\tau^{y}$ is not determinate in sign and can turn out to be a subsidy the regulation suggested in proposition 2 cannot be recommended for practical policy.

\subsection{No Market for Material Content}

The purpose of this subsection is to investigate the case where price signals for material content are missing $\left(\tilde{P}_{q}=0\right)$. This case is of particular interest since recyclability and material content, respectively, is a public good. To reveal the public good character of product design imagine a disaggregated version of our model with many households and recyclers. Since material content is the same for all units the producer sells, every household and every recycler 'consumes' the same material content. Joint consumption is the

\footnotetext{
${ }^{12}$ In the branch of literature studying pollution taxation under different market structures it is usual to assume that subsidizing producers' output is infeasible, whereas taxes, e.g. emission taxes, levied on producers are feasible, compare Barnett (1980), Katsoulacos and Xepapadeas (1995) or Simpson (1995). Katsoulacos and Xepapadeas mention "additional social cost" and Simpson (1995) mentions "structural impediments which prevent the regulator from addressing imperfect competition issues directly".
} 
only constitutive property of public goods. Markets for public goods usually do not emerge in reality. Thus the market-shut down of product design has been intensively discussed by Eichner and Pethig (2001a) and Calcott and Walls (2000) in a perfectly competitive economy. At missing price signals for material content the producer designs the consumption good without taking into account the recycler's needs or wants and the economy exhibits a further distortion, the green design externality (see (c)).

Eq. (14) for $\tilde{P}_{q}=0$ elucidates that the producer chooses $q$ without obtaining any price signals from the monopolistic recycler. As a consequence the recycler takes the level of material content of residuals as exogenously given and exhibits a Nash-like behavior of optimally responding to the 'prevailing' level of $q$. Observe that in this scenario the market allocation $(\hat{z}, \hat{q}, \hat{\alpha})$ is characterized by Eqs. (17), $F_{q}(\hat{q})=\sigma^{m}$ and (19). Comparing the market allocation with the efficient allocation yields

Proposition 3. Suppose there is no market for material content $\left(\tilde{P}_{q}=0\right)$ and set $\sigma^{r}=c^{d}$, $\tau^{y}=c^{d}$ and $\sigma^{m}=\tau^{w}=0$, then

(a) the material content emerging in the monopoly is inefficiently low,

(b) the recycling ratio emerging in the monopoly is inefficiently low,

(c) the amount of recycling services chosen by the recycler is less than the half of the efficient recycling services.

In proposition 3 the deposit-refund system corrects for the environmental externality such that the economy remains with two distortions, namely imperfect competition (b) and the product design externality (c). When markets for product design are missing $\left(\tilde{P}_{q}=0\right)$, producers do not obtain any price signals for material content. As a response they decrease the material content, see proposition 3 (a), and material in order to reduce production costs. Since residuals with lower material content are less productive in the secondary material generation, the recycler produces less recycled material and more waste. The change of material turns out to be smaller than the change of the recycled material since the recycling ratio $\alpha=r /(q y)$ shrinks, see proposition 3 (b). As expected the imperfect competition distortion causes an inefficiently low supply of recycling services, compare proposition 3 (c).

A comparison of proposition 3 with proposition 1 shows that the product design externality is responsible for the fact that the producer chooses an inefficiently low material content and that the recycler chooses an inefficiently low recycling ratio. It is remarkable that the product design externality induces in addition the recycler to lower the supply of recycling services under half of their efficient level.

The necessary insight into the policy issue provides 
Proposition 4. Suppose there is no market for material content $\left(\tilde{P}_{q}=0\right)$ and set $t^{13}$ $\sigma^{m}=\left(c^{w}+c^{d}\right) \alpha^{*}-G_{q}>0, \sigma^{r}=c^{d}, \tau^{y}=c^{d}-\delta y^{*}+\left(c^{w}+c^{d}\right) \alpha^{*}-G_{q}$ and $\tau^{w}=0$. Then the pertinent allocation is efficient.

The proposed tax-subsidy scheme of proposition 4 is quite complex. A subsidy on material input for producing good $Y\left(\sigma^{m}\right)$, a subsidy on recycled material $\left(\sigma^{r}\right)$ and a tax/subsidy on good $Y\left(\tau^{y}\right)$ are necessary to restore efficiency. For the purpose of interpretation we decompose $\tau^{y}$ into three parts $\tau^{y}=\tau_{1}^{y}+\tau_{2}^{y}+\tau_{3}^{y}$ where $\tau_{1}^{y}:=c^{d}, \tau_{2}^{y}:=-\delta y^{*}$ and $\tau_{3}^{y}:=\sigma^{m}$. The policy parameters $\left(\tau_{3}^{y}, \sigma^{m}\right)$ serve to purpose of inducing firm $Y$ to choose the correct green product design. Remember that $G_{q}$ are the marginal unit recycling costs of increasing $q$ and that $\left(c^{w}+c^{d}\right)$ reflect the marginal landfilling costs and the environmental damage caused by increasing the material content, respectively. $\sigma^{m}$ stimulates the producer's demand for material and $\tau_{3}^{y}$ brakes her supply of consumption goods with the consequence that the material content increases. The tax-subsidy combination $\left(\tau_{1}^{y}, \sigma^{r}\right)$ which corrects for the environmental externality on the one side drives back the production of the consumption good and on the other side promotes the production of recycled material such that via (2) the generation of waste is diminished. Last but not least the subsidy $\tau_{2}^{y}$ induces the producer to increase the supply of the consumption good which ensures that the monopolistic recycler increases her demand for recycling services and bridges the inefficiency gap caused by imperfect competition. Since $\tau_{1}^{y}>0, \tau_{2}^{y}<0, \tau_{3}^{y}>0$ the sign of $\tau^{y}$ is indeterminate in sign and since the tax-subsidy scheme listed in proposition 4 is relative complex it is not recommendable for policymakers.

\section{$5 \quad$ Standards and Tax-Subsidy-Schemes}

An alternative to price-based policies is a command and control regulatory standard. As pointed out by Helfand (1981) in the context of a pollution externality there are different forms of standards. Considering a production process with two outputs: a product and a by-product, where the by-product causes an externality, possible forms of standards are restrictions on (a) by-product, (b) by-product per unit of product, (c) product, (d) input, (e) input per unit of product, (f) input per unit of by-product, or (g) the use of particular by-product-control technologies. Instead of analyzing all standards (a) - (g) step by step we restrict our attention to a relative recycling standard which is defined as a minimum quantity of recycled material per unit of embodied material in residuals, a standard of type (6) (strictly speaking of the form: by-product per unit of input). The motivation for dealing with standards in general is the rather critical assessment of policies outlined in

\footnotetext{
${ }^{13} \sigma^{m}$ is strictly positive since $\left(c^{w}+c^{d}\right) \alpha-G_{q}=\frac{\alpha}{q} G_{\alpha}-G_{q}$ which is positive due to (6).
} 
section 4 and for dealing with relative recycling standards in particular is their empirical relevance for the German DSD, see table 1 for past values of these standards. Therefore, in what follows we employ whether relative recycling standards in combination with tax and subsidy instruments are able to bridge the inefficiency gap. Let $\bar{\alpha}$ be the relative recycling standard. The recycler faces the constraint $\alpha \geq \bar{\alpha}$ on her recycling ratio. Assuming the constraint is binding in case of failing markets for product design we have the following constrained optimization problem for the monopolistic recycler ${ }^{14}$

$$
\max _{y} \Pi^{r}=\bar{P}(y, q) y-y G(q, \bar{\alpha})-p^{w}(1-\bar{\alpha} q) y+\sigma^{r} \bar{\alpha} q y
$$

The first-order conditions characterizing the market allocation $(y, q)$ are

$$
\begin{gathered}
\beta-2 \delta y=F(q)+G(q, \bar{\alpha})+\tau^{y}-\sigma^{m} q+c^{w}(1-\bar{\alpha} q)-\sigma^{r} \bar{\alpha} q \\
F_{q}=\sigma^{m} .
\end{gathered}
$$

Again as in subsection 4.3 the producer determines product design without taking into account the recyclers needs $\left(\tilde{P}_{q}=0\right)$. Since the recycling ratio is prescribed the recycler's choice is restricted to the supply of recycling services y. Comparing Eqs. (27), (28) and (8), (9) shows that efficiency requires

$$
\begin{gathered}
\sigma^{m}=\left(c^{w}+c^{d}\right) \bar{\alpha}-G_{q}, \\
\tau^{y}-\sigma^{r} \bar{\alpha} q^{*}=c^{d}\left(1-\bar{\alpha} q^{*}\right)\left(c^{w}+c^{d}\right) q^{*}-G_{q} q^{*}-\delta y^{*} .
\end{gathered}
$$

Introducing a relative recycling standard leaves room for changing the assignment of policy instruments. Whereas in proposition 4 the efficiency-restoring policies $\left(\sigma^{m}, \sigma^{r}, \tau^{y}\right)$ are uniquely determined, using $\left(\bar{\alpha}, \sigma^{m}, \sigma^{r}, \tau^{y}\right)$ the subsidy on material $\sigma^{m}$ has to satisfy (29) whereas convex combinations of $\sigma^{r}$ and $\tau^{y}$ are possible. One promising candidate is suggested in

Proposition 5. Suppose there is no market for material content $\left(\tilde{P}_{q}=0\right)$ and set $\bar{\alpha}=\alpha^{*}$, $\tau^{y}=c^{d}\left(1-\alpha^{*}\right)+\left(c^{w}+c^{d}\right) q^{*}-G_{q} q^{*}>0, \sigma^{m}=\left(c^{w}+c^{d}\right) \alpha^{*}-G_{q}>0$ and $\sigma^{r}=\delta y^{*} /\left(\alpha^{*} q^{*}\right)$. Then the pertinent allocation is efficient.

What is the rationale behind the policy of proposition 5? First, the efficient recycling ratio is directly forced by the relative recycling standard $\bar{\alpha}$. The output tax has two components $\tau^{y}=\tau_{3}^{y}+\tau_{4}^{y}$ where $\tau_{3}^{y}:=\sigma^{m}$ and $\tau_{4}^{y}:=c^{d}(1-\bar{\alpha})$. Second, the policy $\left(\tau_{3}^{y}, \sigma^{m}\right)$ addresses the green design problem, i.e. $\sigma^{m}$ stimulates the use of material and $\tau_{3}^{y}$ stimulates the supply

\footnotetext{
${ }^{14}$ Throughout this section we set $\tau^{w}=0$.
} 
of the consumption good with the consequence that the producer chooses the efficient product design. Third, the recycler obtains a subsidy on recycled material to address the imperfect competition distortion. This subsidy stimulates the recycler to increase her supply of recycling services. Fourth, $\tau_{4}^{y}$ covers the environmental damage and corrects for the environmental externality.

Proposition 5 is quite remarkable when compared with proposition 4 . In proposition 4 (compare also Eqs. (10) and (19)) $\sigma^{r}$ is set equal to $c^{d}$ with the consequence that the consumption good's tax $\tau_{2}^{y}=-\delta y^{*}$ has to provide incentives which correct for the imperfect competition distortion. $\tau_{2}^{y}$ in turn is responsible for the ambiguous sign of $\tau^{y}$ and thus for the reservations against the policy proposed in proposition 4 . In contrast, the introduction of the relative recycling standard ensures that now the subsidy on recycling services is able to cover imperfect competition such that $\tau^{y}$ does not turn out as a subsidy of consumption goods. To sum up, the relative recycling standard in combination with a consumption good's tax, a material subsidy, and a subsidy on recycling services, is a favorable option for practical policy.

\section{Conclusion}

This paper analyzed imperfect competition in the area of product design and solid waste processing. Focusing on market allocations we pointed out that in case of functioning markets for product design producers choose the efficient product design whereas recycling services are inefficiently low due to imperfect competition. Product design and recycling ratio turned out to be independent of the market structures perfect competition or monopoly. This result reminds of Swan's independence result in the context of durability, compare Swan (1970) and Abel (1983). However, proving that product design is independent of the market structure in general requires a model with $n$ oligopolistic recycling firms and remains an issue for further research. It is worth mentioning that our independence results are derived under cost functions which display constant returns to scale. For the cost functions appendix I provides a microeconomic foundation based on linear homogeneous production and recycling technologies which have empirical relevance and are widely applied in economic analyses. However, if we relax the assumption of constant returns to scale the independence results will not hold in general. Turning to the case where the market for product design fails and the imperfect competition distortion is present both the material content and the recycling ratio are inefficiently low. This is caused by the product design externality, not by imperfect competition. Furthermore, the supply of recycling services is lower than the supply of recycling services under imperfect competition when the market for material content works. 
From policy perspective taking into account imperfect competition provides the following insights:

(a) Pure tax-subsidy schemes, i.e. the deposit-refund system as suggested by Calcott and Walls (2000) and Eichner and Pethig (2001a,b) are no recommendable policy options since they are unsuitable for political and practical reasons.

(b) A relative recycling standard combined with a consumption good's tax, a material subsidy and a subsidy on recycling services bridges all inefficiency gaps and has good chances to be implemented in product design and solid waste management.

A final remark relates to the policies which are in use at the DSD in Germany, see Staudt et al. (1997). Although our model does not contain a waste management organization like the DSD, one can imagine that in our model the DSD is incorporated into the production sector and that the DSD has the official permission to regulate producers and recyclers. To be more specific, all production firms that use packages for their consumption goods pay both fees that are material specific $\left(\sigma^{m}\right)$ and fees that are packaging weight specific $\left(\tau^{y}\right)$. In addition, the recycler is paid by the DSD for her recycling services $\left(\sigma^{r}\right)$ and is regulated by a relative recycling standard ${ }^{15}$. To conclude, it is conspicuous that in view of our analysis the policy instruments used by the DSD are conceptual appropriate and in principle will do a good job. Obviously, it is not clear whether these policies are set such that the resulting allocation is approximately in accordance with the efficient one. This question has to be answered with help of applied general equilibrium models which may be an interesting task for further research.

\section{Appendix I: Microfoundations}

Appendix I serves to microfoundate the (ad hoc) cost functions (1) and (5) from a general equilibrium model whose structure is presented in figure 1.

The production cost function: In the economy the consumption good $Y$ is produced with labor $\ell_{y}$ and two types of materials which are embodied in the output according to the strictly concave and linear homogeneous production function ${ }^{16}$

$$
y=Y\left(\begin{array}{c}
\ell_{y}, m \\
+ \\
+
\end{array}\right) .
$$

For simplicity, one of these materials is assumed to be costless and therefore not explicitly introduced into the formal model. The other type of material is an explicit input in the production

\footnotetext{
${ }^{15}$ For more information with respect to the relative recycling standard we refer to the introduction.

${ }^{16}$ Subscripts attached to upper-case letters indicate first derivatives. A plus or minus sign underneath an argument of a function denotes the sign of the respective partial derivative.
} 
process; its quantity is $m$. Each unit of good $Y$ is of constant weight, but the technology (31) allows for varying the material input mix as measured by the material content

$$
q:=\frac{m}{y} \in[0,1]
$$

The linear homogenity of the production function ensures that there is a function $\Upsilon$ increasing and strictly concave, such that $\Upsilon(k)=1 / q$ where $k:=\ell_{y} / m$. Assume further that $\Upsilon$ satisfies the Inada-conditions $\lim _{k \rightarrow 0} \Upsilon_{k}(k)=\infty$ and $\lim _{k \rightarrow \infty} \Upsilon_{k}(k)=0$. For given material price $p_{m}$ and labor price $p_{\ell}$ producers face the costs $p_{m} m+p_{\ell} \ell_{y}$ or equivalently

$$
C(y, q)=y F(q)
$$

where $F(q):=\left[p_{m} q+p_{\ell} q \Upsilon^{-1}\left(\frac{1}{q}\right)\right]$. Having in mind that $\Upsilon^{-1}=: \Xi$ is the inverse function of $\Upsilon$ the properties of the unit production cost function can be written as ${ }^{17}$

$$
\begin{gathered}
F_{q}=p_{m}+p_{\ell} \Xi\left(\frac{1}{q}\right)+p_{\ell} q \Xi^{\prime}\left(\frac{1}{q}\right)\left(-\frac{1}{q^{2}}\right)=p_{m}+p_{\ell} \Xi\left(\frac{1}{q}\right)-\frac{p_{\ell} \Xi^{\prime}\left(\frac{1}{q}\right)}{q}, \\
F_{q q}=-\frac{p_{\ell} \Xi^{\prime}\left(\frac{1}{q}\right)}{q^{2}}-\frac{\left[p_{\ell} \Xi^{\prime \prime}\left(\frac{1}{q}\right)\left(-\frac{1}{q^{2}}\right) q-p_{\ell} \Xi^{\prime}\left(\frac{1}{q}\right) 1\right]}{q^{2}}=\frac{p_{\ell} \Xi^{\prime \prime}\left(\frac{1}{q}\right)}{q^{3}}>0 .
\end{gathered}
$$

Property 1. Suppose the production function $Y$ is linear homogeneous and satisfies the Inada-conditions, then the associated unit production cost function $F$ is u-shaped.

In the proofs of properties 1 and 2 we make use of

Lemma 1. Let $S: \mathbb{R}_{+} \rightarrow \mathbb{R}_{+}$with $s=S(y)$. Suppose $S(0)=0$ and $S^{\prime}(y)>0$, then

$$
S^{\prime \prime}(y)>0 \quad \Longleftrightarrow \quad S^{\prime}(y)>\frac{S(y)}{y} .
$$

Lemma 1 can be proven by application of the mean value theorem of differential calculus.

Proof of property 1: The Inada conditions carried over to the function $\Xi$ are

$$
\begin{aligned}
& \lim _{\frac{1}{q} \rightarrow 0} \Xi^{\prime}\left(\frac{1}{q}\right)=\lim _{q \rightarrow \infty} \Xi^{\prime}\left(\frac{1}{q}\right)=0, \\
& \lim _{\frac{1}{q} \rightarrow \infty} \Xi^{\prime}\left(\frac{1}{q}\right)=\lim _{q \rightarrow 0} \Xi^{\prime}\left(\frac{1}{q}\right)=\infty .
\end{aligned}
$$

From lemma 1 we know that

$$
\Xi^{\prime \prime}\left(\frac{1}{q}\right)>0 \quad \Longleftrightarrow \quad\left[\frac{\Xi\left(\frac{1}{q}\right)}{\frac{1}{q}}-\Xi^{\prime}\left(\frac{1}{q}\right)\right]<0 .
$$

\footnotetext{
${ }^{17}$ Observe that $\Upsilon_{k}>0$ and $\Upsilon_{k k}<0$ imply $\Xi^{\prime}\left(\frac{1}{q}\right)>0$ and $\Xi^{\prime \prime}\left(\frac{1}{q}\right)>0$.
} 
In view of (34) and (36) we find that $\lim _{q \rightarrow \infty} F_{q}>0$. Next using (37) and (38) yields

$$
\lim _{q \rightarrow 0} F_{q}=\lim _{q \rightarrow 0}\left[p_{m}+p_{\ell} \frac{1}{q}\left[\frac{\Xi\left(\frac{1}{q}\right)}{\frac{1}{q}}-\Xi^{\prime}\left(\frac{1}{q}\right)\right]\right]=-\infty .
$$

Finally, the strict convexity of $F$ ensures that there exists a $\tilde{q}$ with

$$
q\{\gtreqless\} \tilde{q} \quad \Longleftrightarrow \quad F_{q}\{\gtreqless\} 0
$$

which establishes property 1.

The net-recycling cost function: With the help of labor $\ell_{r}$ material is reclaimed from residuals according to the strictly concave and linear homogeneous recycling technology

$$
r=R\left(\begin{array}{c}
\ell_{r}, s \\
++
\end{array}\right)
$$

where $s:=A(q) y$. It is plausible to assume that the function $A$ satisfies $A(0)=0, A_{q}>0$ and $A_{q q}>0$. Recycled material and virgin material are assumed to be perfect substitutes and virgin material extraction is assumed to take place under constant returns to scale, with unit extraction cost of $p_{m}$. Then the recycling firm receives the revenue $p_{m} r=p_{m} \alpha q y:=E(\underset{+}{y}, \underset{+}{q}, \underset{+}{\alpha})$ from the sale of recycled material and she incurs the labor costs $p_{\ell} \ell_{r}$. Using the linear homogenity property of the recycling function there exists a function $\Phi$, strictly concave and increasing, such that $\Phi(n)=r / s$ where $n:=\ell_{r} / s$. Taking the inverse function of $\Phi, \Omega:=\Phi^{-1}$, inserting $s=A(q) y$ and (3) we obtain the recycling cost function $K(y, q, \alpha):=p_{\ell} A(q) y \Omega\left(\frac{\alpha q}{A(q)}\right)=p_{\ell} \ell_{r}$. The recycling cost function is increasing in $\alpha$ due to ${ }^{18}$

$$
K_{\alpha}=p_{\ell} q y \Omega^{\prime}\left(\frac{\alpha q}{A(q)}\right)>0
$$

whereas

$$
K_{q}=p_{\ell} y\left[A^{\prime}(q) \Omega\left(\frac{\alpha q}{A(q)}\right)+\frac{\alpha \Omega^{\prime}\left(\frac{\alpha q}{A(q)}\right)}{A(q)}\left(A(q)-q A^{\prime}(q)\right)\right]
$$

is ambiguous in sign. Although we find it plausible that recycling costs should decrease as the material content goes up, which is satisfied for recycling functions of the parametric form $r=$ $\ell_{r}^{\beta}\left(q^{2} y\right)^{1-\beta}$ with $\beta<0.5$ owing to $K_{q}=p_{\ell} y\left(\alpha-\frac{1}{\beta}\right) \frac{\alpha^{\frac{1}{\beta}}}{q^{\frac{1-\beta}{\beta}}}$, we do not restrict $K_{q}$ to be decreasing in $q$. Finally, the net-recycling cost function is secified as

$$
N(y, q, \alpha):=K(y, q, \alpha)-E(y, q, \alpha):=y G(q, \alpha)
$$

where $G(q, \alpha):=p_{\ell} A(q) \Phi^{-1}\left(\frac{\alpha q}{A(q)}\right)-p_{m} \alpha q$.

\footnotetext{
${ }^{18}$ Note that $\Omega^{\prime}\left(\frac{\alpha q}{A(q)}\right)>0$ and $A(q)-q A^{\prime}(q)<0$. The latter inequality follows from applying lemma 1 .
} 
Property 2. Suppose the recycling function $R$ is linear homogeneous, then the associated net-unit recycling cost function $F$ satisfies $\alpha G_{\alpha}-q G_{q}>0$.

Proof: Using the partial derivatives of $G$ implies after some rearrangements

$$
\frac{\alpha}{q} G_{\alpha}(q, \alpha)-G_{q}(q, \alpha)=p_{\ell} A^{\prime}(q)\left[\frac{\alpha q}{A(q)} \frac{\partial\left(\Omega\left(\frac{\alpha q}{A(q)}\right)\right)}{\partial\left(\frac{\alpha q}{A(q)}\right)}-\Omega\left(\frac{\alpha q}{A(q)}\right)\right] .
$$

Defining $t:=\frac{\alpha q}{A(q)}$ turns (44) into

$$
\frac{\alpha}{q} G_{\alpha}(q, \alpha)-G_{q}(q, \alpha)=p_{\ell} A^{\prime}(q)\left[\Omega^{\prime}(t) t-\Omega(t)\right] .
$$

$\Omega$ is increasing and strictly convex and applying lemma 1 proves property 2 .

\section{Appendix II: Proofs}

Proof of proposition 1: Let $\left(x^{M}, q^{M}, \alpha^{M}\right)$ be the solution to (17) - (19). Inserting $\tau^{y}=$ $\sigma^{r}=c^{d}$ and $\sigma^{m}=\tau^{w}=0$ into (18) - (19) shows that these equations are identical to (9) - (10) which both are independent of $y$ and determine $q^{*}$ and $\alpha^{*}$. So far we have demonstrated that $q^{*}=q^{M}$ and $\alpha^{*}=\alpha^{M}$. Finally, observe that the RHSs of (8) and (17) are equal which establishes $2 y^{M}=y^{*}$.

Proof of proposition 3: To prove that the material content in the market is inefficiently low we compare $F_{q}(\hat{q})=0$ with

$$
F_{q}\left(q^{*}\right)=\frac{\alpha^{*}}{q^{*}} G_{\alpha}\left(q^{*}, \alpha^{*}\right)-G_{q}\left(q^{*}, \alpha^{*}\right)
$$

Combining (46) and property 2 then $F_{q}\left(q^{*}\right)>0$ is straightforward. In light of property $1 F_{q}\left(q^{*}\right)>$ 0 and $F_{q}(\hat{q})=0$ implies $\hat{q}<q^{*}$.

Now we pay attention to the recycling ratio which both in the market and in the social optimum for given $q$ is characterized by

$$
G_{\alpha}(q, \alpha)=\left(c^{w}+c^{d}\right) q .
$$

Eq. (47) is equivalent to

$$
p_{\ell} \Omega^{\prime}\left(\frac{\alpha q}{A(q)}\right)-p_{m}-\left(c^{w}+c^{d}\right)=0
$$


Total differentiation of Eq. (48) yields:

$$
\frac{d \alpha}{d q}=-\frac{\Omega^{\prime \prime}\left(\frac{\alpha q}{A(q)}\right)\left[\frac{\alpha A(q)-\alpha q A^{\prime}(q)}{A(q)^{2}}\right]}{\Omega^{\prime \prime}\left(\frac{\alpha q}{A(q)}\right) \frac{q}{A(q)}}=\frac{\alpha}{q A(q)}\left[q A^{\prime}(q)-A(q)\right] .
$$

Using lemma 1 we get

$$
A^{\prime \prime}(q)>0 \quad \Longleftrightarrow \quad q A^{\prime}(q)-A(q)>0 \quad \Longleftrightarrow \quad \frac{d \alpha}{d q}>0
$$

which establishes proposition 3 (b).

Finally, we prove proposition 3 (c). Inserting (8) into (9) and (17) into (19) yields

$$
y^{*}=2 \hat{y}=\beta-F(q)-G(q, \alpha)-\left(\frac{1}{q}-\alpha\right) G_{\alpha}(q, \alpha)=: z .
$$

Differentiation with respect to $q$ we get

$$
d z=\left[-F_{q}-G_{q}+\frac{1}{q^{2}} G_{\alpha}-\left(\frac{1}{q}-\alpha\right) G_{\alpha q}\right] d q+\left[-G_{\alpha}+G_{\alpha}-\left(\frac{1}{q}-\alpha\right) G_{\alpha \alpha}\right] \frac{d \alpha}{d q} d q .
$$

Substituting (49) and

$$
\begin{gathered}
G_{\alpha \alpha}=p_{\ell} \frac{q^{2}}{A(q)} \Omega^{\prime \prime}\left(\frac{\alpha q}{A(q)}\right) \\
G_{\alpha q}=p_{\ell} \Omega^{\prime}\left(\frac{\alpha q}{A(q)}\right)+p_{\ell} \frac{\alpha q}{A(q)^{2}} \Omega^{\prime \prime}\left(\frac{\alpha q}{A(q)}\right)\left[A(q)-q A^{\prime}(q)\right],
\end{gathered}
$$

after some rearrangements we obtain

$$
\frac{d z}{d q}=p_{\ell} A^{\prime}(q)+\left[\frac{\alpha q}{A(q)} \Omega^{\prime}\left(\frac{\alpha q}{A(q)}\right)-\Omega\left(\frac{\alpha q}{A(q)}\right)\right]>0
$$

which is positive according to lemma 1 . From $d z / d q>0$ and $q^{*}>\hat{q}$ we infer $y^{*}>\hat{z}=2 \hat{y}$.

Propositions 2, 4 and 5 are straightforward from inserting the policy parameter values into the conditions which characterize the market allocation and then comparing them with Eqs. (8) - (10).

\section{References}

Abel A. B. (1983): "Market structure and the durability of goods", Review of Economic Studies 50, pp. 625-637.

Barnett A. H. (1980): "The Pigouvian tax rule under monopoly", American Economic Review 70, pp. 1037-1041. 
Baumol W. J., Oates W. E. (1998): The theory of Environmental Policy, second Edition, Cambridge University Press, Cambridge.

Buchanan J. (1969): "External diseconomies, corrective taxes, and market structure", American Economic Review 59, pp. 174-177.

Calcott K., Walls M. (2000): "Can downstream waste disposal policies encourage upstream 'design for environment'?", American Economic Review 90, pp. 233-237.

Choe C., Fraser I. (1999): "An economic analysis of household waste management", Journal of Environmental Economics and Management 38, pp. 234-246.

Fullerton D., Wolverton A. (2000): "Two generalizations of a deposit-refund system", American Economic Review 90, pp. 238-242.

Fullerton D., Wu W. (1998): "Policies for green design", Journal of Environmental Economics and Management 36, pp. 131-148.

Eichner T., Pethig R. (2001a): "Product design and efficient management of recycling and waste treatment", Journal of Environmental Economics and Management 41, pp. 109-134.

Eichner T., Pethig R. (2001b): "Recycling, producer responsibility and centralized waste management", FinanzArchiv 57, pp. 333-360.

Gaudet G., Van Long N. (1999): "Noncompetitive recycling and market power", Discussion paper, Université de Montréal.

Grant D. (1999): "Recycling and market power: a more general model and reeveluation of the evidence", International Journal of Industrial Organization 6, pp. 489-497.

Helfand E. G. (1991): "Standards versus standards: the effects of different pollution restrictions", American Economic Review 81, pp. 622-634.

Holm-Müller K. (1996): "Die Verwertung des deutschen Abfallrechts im Lichte des MaterialBilanz-Ansatzes", Jahrbuch der Wirtschaftswissenschaften 47, pp. 311-323.

Katsoulacos Y., Xepapadeas A. (1995): "Environmental policy under oligopoly with endogeneous market structure", Scandinavian Journal of Economics 97, pp. 411-420.

Mommer L. J. (2000): "Waste disposal market and relative standards", Discussion paper V-206-00, University of Oldenburg.

Rousso A. S., Shah S. P. (1994): "Packaging taxes and recycling incentives: the german green dot programme", National Tax Journal 47, pp. 689-701. 
Sheshinsky E. (1976): "Price, quality, and quantity regulation in monopoly situations", Economica 43, pp. 127-137.

Staudt E., Kunhenn H., Scholl M., Interthal J. (1997): Die Verpackungsordnung. Auswirkungen eines umweltpolitischen Grossexperimentes, Innovation: Forschung und Management, Band 11, Bochum.

Simpson R. D. (1995): "Optimal pollution taxation in a Cournot duopol", Environmental and Resource Economics 6, pp. 359-369.

Swan P. L. (1970): "Durability of consumption goods", American Economic Review 60, pp. 884-894.

Tirole J. (1988): The Theory of Industrial Organization, , MIT press, Cambridge. 